\title{
Seismic Design Loads of Truss Arch Frames with Ceilings subjected to Vertical and Horizontal Earthquake Motions
}

\author{
Koichiro Ishikawa
}

Bunkyo 3-9-1, Fukui-shi, Fukui-ken, Department of Architecture and Civil Engineering, University of Fukui, Japan

\begin{abstract}
Spatial structures such as a gymnasium and an exhibition hall often use ceilings because of enhancing sound effects and reducing heating bills. Although the ceiling members fell down on a large scale due to the seismic motion according to the past great earthquake disaster reports, structural engineers particularly do not carry out the seismic design. The study gives structural engineers the equivalent static loads for the design of the earthquake-proof design of the ceiling system. In particular, it is significant to investigate the dynamic behavior and the applied seismic loads for the complicated vibration of the long span arch building structures with RC columns.
\end{abstract}

Key words: Truss arch frame, RC column, Knee brace, Vertical and horizontal earthquake motions, Earthquake-proof design, Equivalent static load, Dominant natural mode

\section{Introduction}

Long span building structures sometimes set up ceiling systems for insulation to reduce heating bills and soundproofing to use as an auditorium. Although the earthquake-proof design for the non-structural member of the ceiling system is necessary to prevent the fall due to the vibration, the design is not carried out as well as the other non-structural member. It is also known by reports on the past earthquake disasters that ceiling boards of spatial structures fall down due to the dynamic response of the roof. In particular, the ceiling board is dangerous to human life staying in the building.

The purpose of this study is to investigate the earthquake response such as the acceleration, the velocity, the displacement and the axial force of long span arch truss frames subjected to vertical and horizontal earthquake motions. Based on the dynamic response, the practical calculation method is shown to predict the equivalent static load for the earthquake- proof design of the ceilings as well as the long span truss arch frames. As long as the accuracy verification of the equivalent static load is concerned, the collapse mechanism and the axial stress of the frames subjected to the static loads show a good agreement with the earthquake response analyses subjected to the earthquake motions.

In the practical calculation method, the distribution and the value of the equivalent static load are calculated by means of the participation vector and the earthquake acceleration response spectrum. The static earthquake-proof design is able to carry out using the equivalent seismic loads practically. In general, it is not easy to predict the distribution of the acceleration response because of the complicated dynamic behavior combined with the vertical and horizontal response of the arch shape beam. This is a reason why the earthquake static load is required for the earthquake-proof design using the static analysis. 


\section{Long Span Truss Arch Frames with} Ceilings supported by RC Columns Subjected to Vertical and Horizontal Earthquake Motions

\subsection{Seismic Design Coefficient of Ceilings}

Seismic design coefficients of arch beams and ceilings are neccesary to calucalate the design seismic load applied at the beam and ceiling for their safety verification.

The ceiling response (E) is shown in Fig.1 is induced by the floor response (D) due to ground motion (B) with amplification characteristics of the surface layer (the layer B) in relation to predominant periods of the layer. The input ground motion $(\mathrm{C})$ for the design is to be defined for the engineering bedrock (the layer A), with the shear wave velocity being about $400 \mathrm{~m} / \mathrm{s}$ or more.
The inertia force $\mathrm{F}_{\mathrm{H}}$ must be set up considering the most important factors as follows:

$$
\begin{gathered}
\mathrm{F}_{\mathrm{H}}=\mathrm{K}_{\mathrm{H}} \mathrm{W} \\
\mathrm{K}_{\mathrm{H}}=\mathrm{Z} \beta_{\mathrm{H}} \mathrm{k}_{\mathrm{H}} \mathrm{K}_{0}
\end{gathered}
$$

Where $K_{H}=$ the seismic design coefficient, $W=$ the weight of the ceiling, $Z=$ the seismic hazard zoning coefficient, $\mathrm{k}_{\mathrm{H}}=$ the seismic design coefficient determined by the roof amplification ratio, $\beta_{\mathrm{H}}=$ the seismic design coefficient determined by ceiling amplification ratio, and $\mathrm{K}_{0}=$ the standard seismic design coefficient.

\subsection{Analysis Model}

The elastic earthquake response analysis is carried out in order to investigate the amplification characteristics at the ceiling board using the analysis model shown in Fig.2. The analysis model deals with the truss arch frame which has around $20 \mathrm{~m}$ in the span,

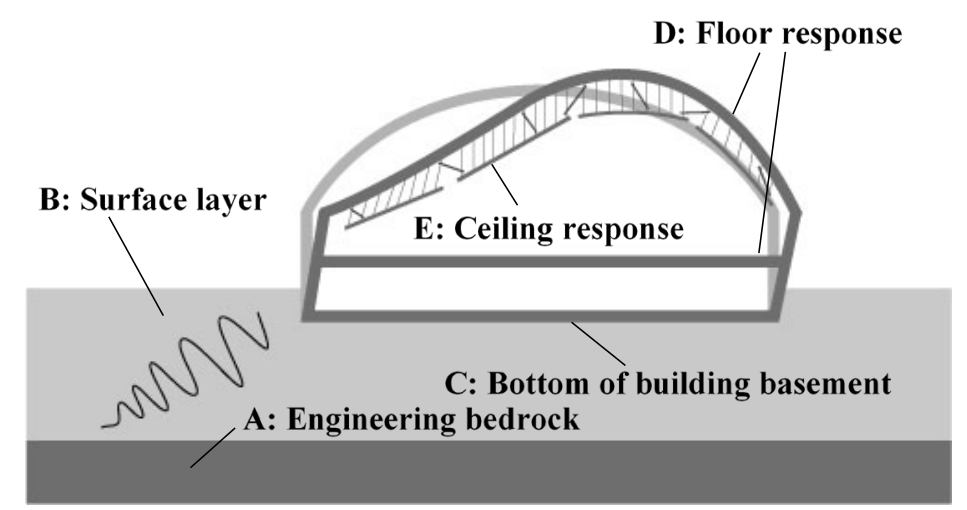

Fig. 1 Response Evaluation of the Arch Beam and the Ceiling.

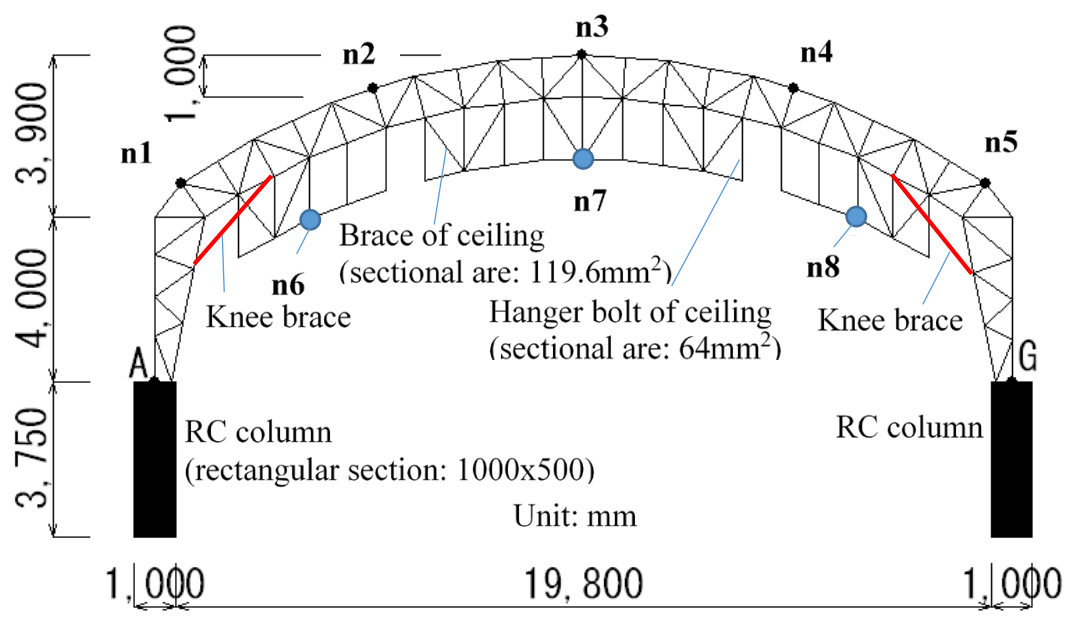

Fig. 2 Truss Arch Frame with Ceiling and Knee Brace. 
Table 1 Member Sectional Area $\left(\mathrm{mm}^{2}\right)$ of the Truss Arch Frame and the Ceilings.

\begin{tabular}{|c|c|c|c|c|}
\hline $\begin{array}{c}\text { arch beam } \\
\text { member }\end{array}$ & $\begin{array}{l}\text { upper } \\
\text { chord }\end{array}$ & $\begin{array}{l}\text { lower } \\
\text { chord }\end{array}$ & $\begin{array}{l}\text { diagonal } \\
\text { web }\end{array}$ & $\begin{array}{l}\text { post } \\
\text { web }\end{array}$ \\
\hline $\mathrm{n} 1-\mathrm{n} 2, \mathrm{n} 4-\mathrm{n} 5$ & 2724 & 5952 & 1745.4 & 2444 \\
\hline n2-n4 & 2724 & 1745.4 & 1160.4 & 2444 \\
\hline column & outer & inner & diagonal & knee \\
\hline member & chord & chord & web & brace \\
\hline left & 5842 & 5842 & 3800 & 5842 \\
\hline right & 5842 & 5842 & 3800 & 5842 \\
\hline
\end{tabular}

$7.9 \mathrm{~m}$ in the ridge height and $12.19 \mathrm{~m}$ in the eaves height. The span-depth ratio $\alpha$ is taken to be 20 . The fundamental natural period of the arch structure results in 0.372 second as a result of the eigenvalue analysis. The ceiling has a symmetry system which is divided into 4 parts as shown in Fig.2. The Rayleigh damping is used for the analysis and the damping ratio is taken to be $2 \%$. The Newmark $\beta$ method is used for solving the vibration equation. As far as a boundary condition is concerned, the bottom of the RC column is set up to be a fix support. The bottoms of two steel truss columns are set up to an anchor bolt and a steel base plate attached by the RC column at the node A and G as shown in Fig.2.

\section{Long Span Truss Arch}

\subsection{Estimation Method of the Maximum Response} Acceleration and the Static Equivalent Static Seismic Load applied at the Beams and the Ceilings

In the earthquake-proof design of the truss arch frame and the ceiling, the design seismic load is calculated considering both of the roof and the ceiling amplification with respect to the vibration characteristics of the truss arch frame. On the other hand, the methodology and the calculation standard are not enough to calculate the seismic design load. The practical estimation method is proposed by means of the seismic response spectrum and the participation factor.

The estimation equation of the maximum response acceleration of each node in the truss arch frame and the ceilings is proposed and verified with respect to the accuracy in comparison with the dynamic numerical analysis.

The maximum acceleration of the node " $\mathrm{j}$ " in the "i"th vibration mode is given as follows:

$$
A c c_{i j}=\beta_{i} S_{A}\left(T_{i}, h_{i}\right) D_{i j}
$$

Where $A c c_{i j}$ is the estimated acceleration of the node " $\mathrm{j}$ ". $\beta_{i}$ is the modal participation coefficient of the " $\mathrm{i}$ "th vibration mode. $S_{A}\left(T_{i}, h_{i}\right)$ is the acceleation response spectrum with respect to the " $\mathrm{i}$ " th natural period $T_{i}$ and damping ratio $h_{i}$. And $D_{i j}$ is the " $\mathrm{i}$ "th vbration mode value of the node " $\mathrm{j}$ ".

The earthquake-proof design of building structures is carried out by means of the static analysis using the seismic load and the load distribution. The static seismic load distribution is also used in the design of the long span truss arch structure. The horizontal distribution of the arch beam is affected by the first vibration mode value and the vertical distribution is affected by the second vibration mode, respectively.

The horizontal static seismic load " $F_{j}^{H}$ " at the node " $\mathrm{j}$ " are given by using the first modal participation coefficient $\beta_{1}$ and the first mode value $\mathrm{D}_{1 \mathrm{~J}}^{\mathrm{H}}$.

$$
F_{j}{ }^{H}=m_{j} \beta_{1} S_{A}^{H}\left(T_{1}, h_{1}\right) D_{1 j}^{H}
$$

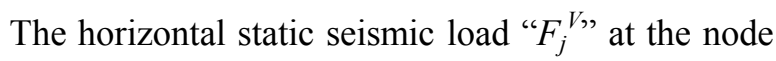
"j" are given by using the second modal participation coefficient $\beta_{2}$ and the second mode value $\mathrm{D}_{2 \mathrm{j}}{ }^{\mathrm{V}}$.

$$
F_{j}^{V}=m_{j} \beta_{2} S_{A}^{V}\left(T_{2}, h_{2}\right) D_{2 j}^{V}
$$

The horizontal seismic load of the design static is given by 
Where

$$
F_{j}^{H}=S_{j}^{H} C_{0}^{H} \sum_{i=1}^{N} w_{i}
$$

$$
C_{o}{ }^{H}=S_{A}{ }^{H}\left(T_{1}, h_{1}\right) / g, \quad S_{j}{ }^{H}=\frac{m_{j} \cdot D_{1 j}^{H}}{\sum_{i=1}^{N} m_{i}}
$$

$m_{j}$ is mass of node " $\mathrm{j}$ ", $D_{l j}$ is the first vibration mode value at node "j", $w_{i}$ is the weight at node "ij", $S_{A}{ }^{H}\left(T_{1}\right.$, $h_{1}$ ) is the acceleation response spectrum (Fig.5) with respect to the first natural period $T_{l}$ and damping ratio $h_{l}=0.02$ and $\mathrm{g}$ is the gravity acceleration. by

The vertical seismic load of the design static is given

$$
C_{o}{ }^{V}=S_{A}{ }^{V}\left(T_{2}, h_{2}\right) / g, \quad S_{j}{ }^{V}=\frac{m_{j} \cdot D_{2 j}^{V}}{\sum_{i=1}^{N} m_{i}}
$$

$m_{j}$ is the mass at node " $j$ ", the second natural period $T_{2}$ acceleration.

\subsection{Vibration Characteristics such as Natural Period and Mode of Truss Arch Frame with Ceiling}

The two natural periods and the vibration modes of the truss arch frame with the ceiling and the knee brace are obtained by means of the eigenvalue analysis, respectively. The first and the second natural periods such as $T_{1}$ and $T_{2}$ are shown in Fig.3. The two corresponding vibration modes are also shown in Fig.3, respectively. It is seen that the horizontal vibration shape of an arch beam appears in the first vibration mode. On the other hand, the vertical vibration shape of an arch beam appears in the second vibration mode. The study focuses on the horizontal and vertical earthquake response of the arch beam and the ceilings subjected to horizontal and vertical earthquake motions. and damping ratio $h_{2}=0.02$ and $\mathrm{g}$ is the gravity
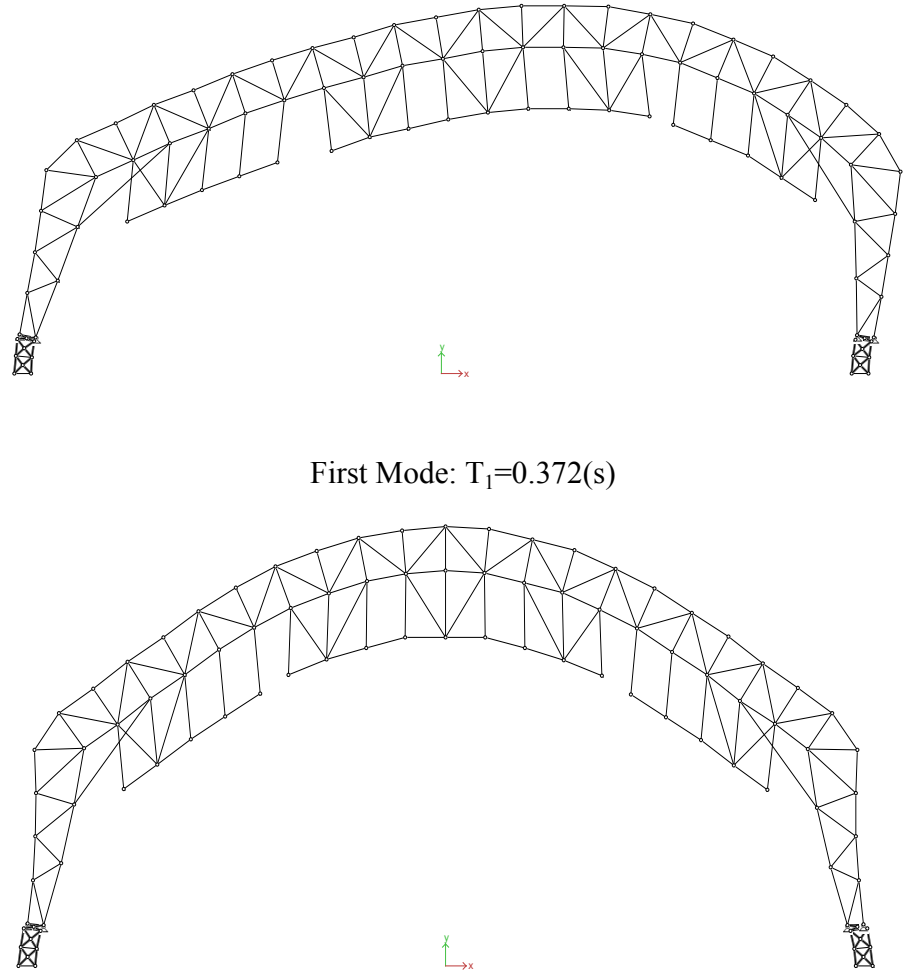

Second Mode: $\mathrm{T} 2=0.168(\mathrm{~s})$

Fig. 3 The First and Second Vibration Modes and Natural Periods $T_{1}$ and $T_{2}$. 


\subsection{Elastic Dynamic Analyses of Truss Frames Subjected to Earthquake Motions}

The elastic earthquake response analysis of the truss arch frame with the ceiling and the knee brace is carried out to verify the accuracy of the estimation value of the seismic load applied at the arch beam and the ceiling by means of the proposed method. The numerical integration method uses the Newmark $\beta$ method in the vibration equation. Since it has been known that the case of $\beta=1 / 4$ will be unconditionally stable for most nonlinear problems, $\beta=1 / 4$ is used in this study. The Rayleigh damping is used and both of the first and second damping factors are taken to be 0.02 .

\subsection{Input Vertical and Horizontal Artificial Earthquake Motions on Surface Ground}

In conventional earthquake-response analysis, the most common approaches to use waves observed either at the ground surface of a certain location, or at the basement or ground floor of a building as the input ground motion.

The basic thinking behind setting up input ground motion for the seismic design and the analyses is described in this section. There are two basic focal points:

(1) Designing is to basically a two-phase design procedure, Level 1 (moderate earthquake motion) and Level 2(severe earthquake motion), with seismic design carried out for these earthquake inputs.

(2) The input ground motion for design calculates considering the amplification of the surface layer from the basement layer with the shear wave velocity such as about $400 \mathrm{~m} / \mathrm{s}$ or more.

The dynamic analysis of the truss structure with ceiling is carried out using the vertical and horizontal motions. The artificial seismic waves with the phase of the five observed earthquake motions are used. The surface layer amplification is considered in the waves. The motion fits the target acceleration response spectrum in Fig.4 of the damage limit artificial earthquake motion with a phase characteristic (Level 1) and the damping factor 0.05 . The peak ground accelerations of the vertical and the horizontal earthquake motions are shown in Table 1 respectively. The average value of the horizontal and vertical motions is 119 and $62 \mathrm{~cm} / \mathrm{sec}^{2}$ respectively.

The acceleration response spectrum $\mathrm{S}_{\mathrm{A}}(\mathrm{T}, \mathrm{h}=0.02)$ in case of the damping factor $\mathrm{h}=0.02$ is shown in Fig. 5 using the input horizontal and vertical earthquake motions. The spectrum such as $\mathrm{S}_{\mathrm{A}}{ }^{\mathrm{H}}(\mathrm{T}, \mathrm{h})$ and $\mathrm{S}_{\mathrm{A}}{ }^{\mathrm{V}}(\mathrm{T}, \mathrm{h})$ are used in the proposed equations (6) and (7).

\subsection{Comparison of the Analyses and the Proposed Method}

The earthquake response analyses are carried out to verify the accuracy of Eqs. (4) and (6) by using the damage limit earthquake motions with the phase of the observed earthquake motions. It is seen in Figs. 6 and 7 that the estimation values of the maximum force and displacement by means of Eqs. (3), (6) and (7) show a good agreement with the time history analyses in the both cases of $\alpha=20$. It is noted that the estimation values are calculated by using just the first modal participation coefficient and the first vibration mode value.

Table 2 PGA (Peak ground acc.: $\mathrm{cm} / \mathrm{sec}^{2}$ ) of the Used Input Earthquake Motion

\begin{tabular}{ll}
\hline Used phase characteristic & PGA \\
\hline El Centro-NS (1940) & 112 \\
Taft-EW (1952) & 129 \\
Hachinohe-NS (1968) & 120 \\
Tohoku-NS (1978) & 102 \\
Kobe-NS (1995) & 133 \\
\hline & \\
\hline Used phase characteristic & PGA \\
\hline El Centro-UD (1940) & 62 \\
Taft-UD (1952) & 57 \\
Hachinohe-UD (1968) & 75 \\
Tohoku-UD (1978) & 64 \\
Kobe-UD (1995) & 52 \\
\hline
\end{tabular}


Journal of Mathematics and System Science 7 (2017) 308-315

doi: $10.17265 / 2159-5291 / 2017.11 .002$

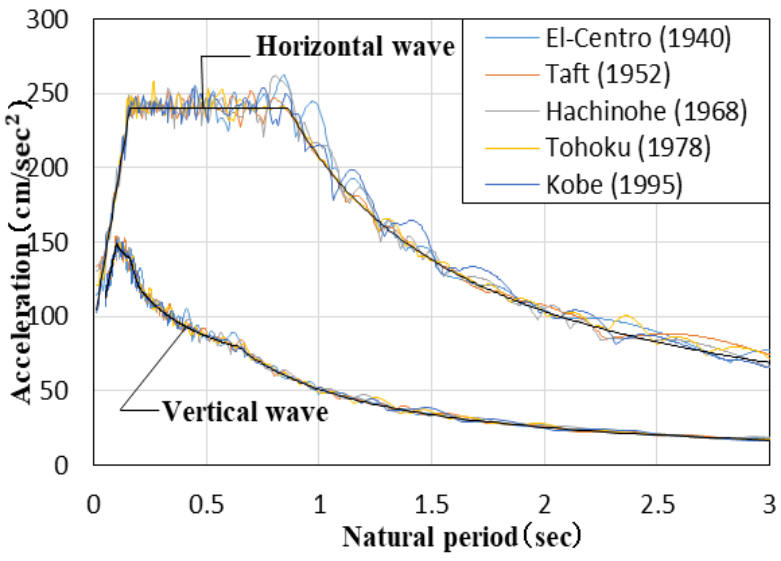

Fig. 4 Target Acceleration response Spectrum (damping factor $h=0.05$ ) of the Damage Limit Artificial Earthquake Motion with a Phase Characteristic (Level 1) (moderate earthquake motion).

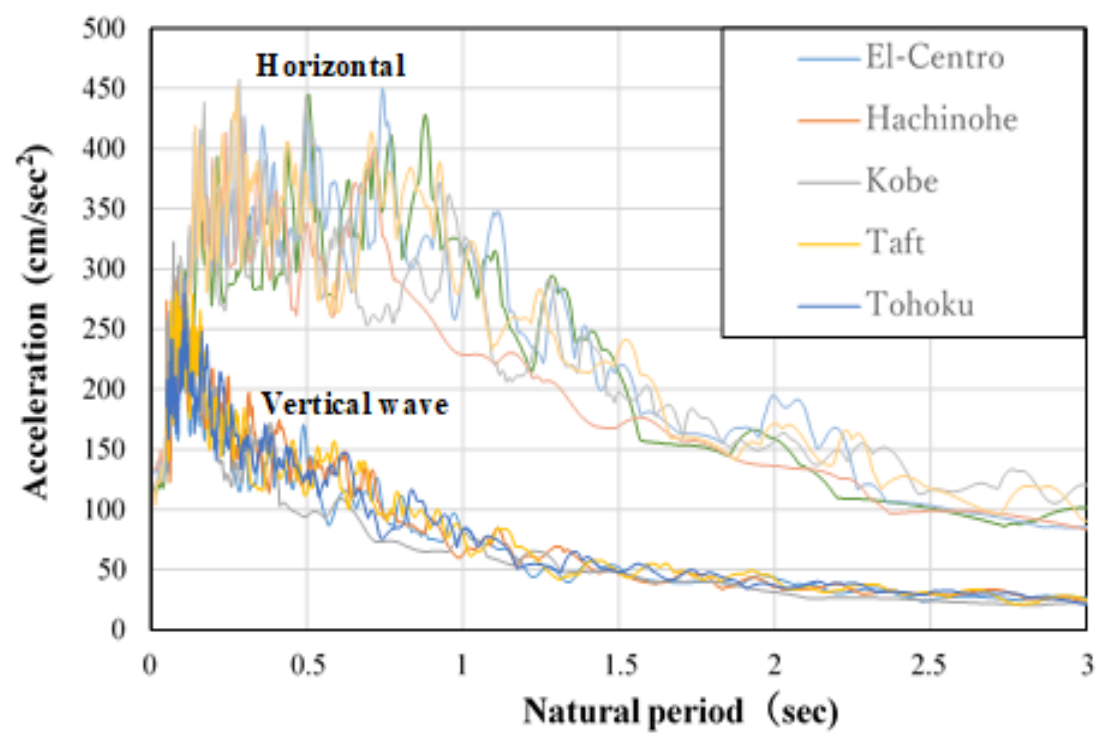

Fig. 5 Acceleration Response Spectrum (damping factor $h=0.02$ ) of the Damage Limit Artificial Earthquake Motion with a Phase Characteristic (Level 1) (moderate earthquake motion).

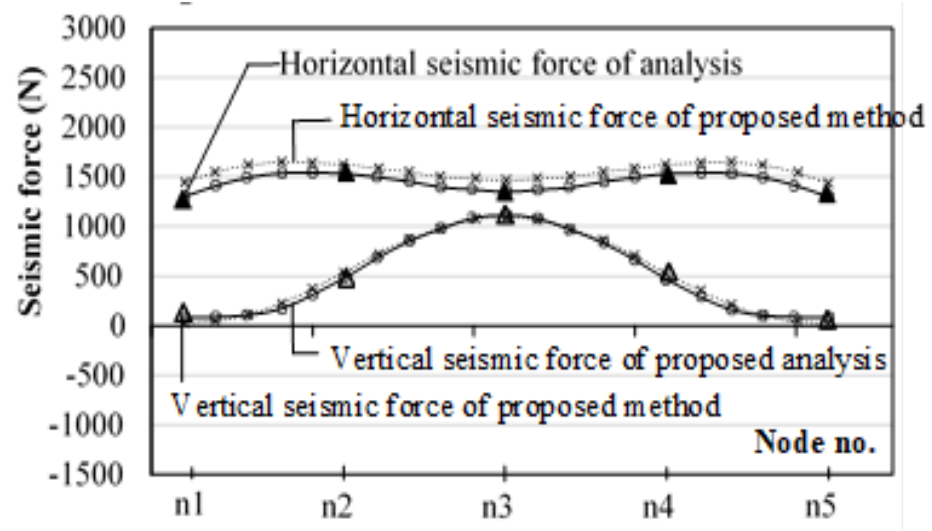

Fig. 6 Distribution of Equivalent Seismic Force at the Arch Truss Beam. 


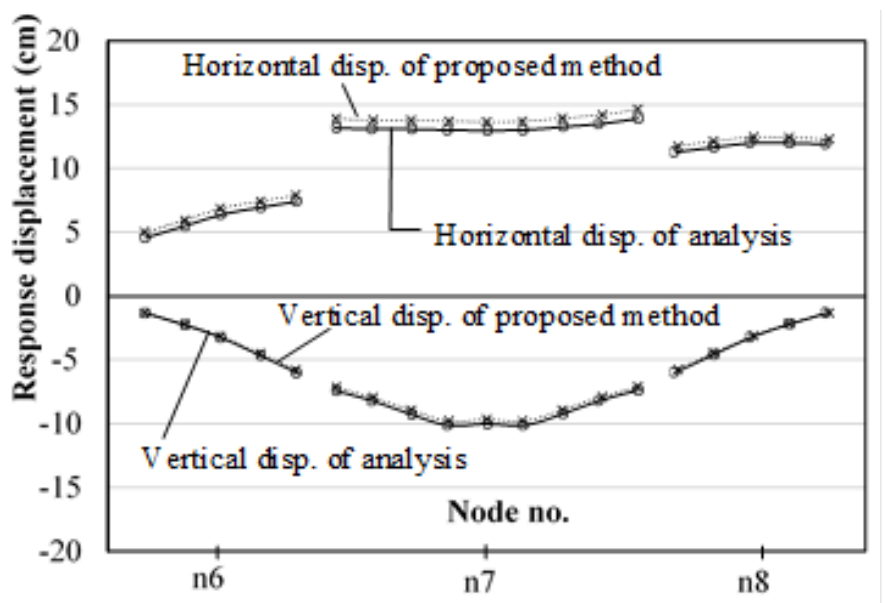

Fig. 7 Distribution of Seismic Force at the Ceiling.

\section{Conclusion}

The characteristic response of the arch beam and the ceiling occurs in the truss arch frame subjected to vertical and horizontal earthquake motions. The design seismic coefficient of the applied load distribution considering the vertical response effect is also actually necessary for the safety study in the earthquake proof design. The study proposes the estimation method of calculating the design seismic coefficient for the applied load for the earthquake-proof design of the long span truss arch frame. The coefficient is easily obtained by means of the eigenvalue analysis. The accuracy is also verified by a good agreement with the earthquake response analysis of the truss arch frames with the ceiling and the knee brace subjected to the damage limit artificial vertical and horizontal earthquake motions. The proposed method of predicting the equivalent static seismic loads can be used to obtain the stress and the deformation for the seismic design.

\section{Acknowledgment}

This work was supported by JSPS KAKENHI Grant Number 15K06290.

\section{References}

[1] K. Ishikawa, Effects of resonance between spatial structures and ceiling systems on the seismic response",
Proceedings of the International Association for Shell and Spatial Structures (IASS) Symposium 2009, Valencia Evolution and Trends in Design, Analysis and Construction of Shell and Spatial Structures Universidad Politecnica de Valencia, Spain Alberto DOMINGO and Carlos LAZARO (eds.), (2009)

[2] K. Ishikawa, S. Okubo, Y. Hiyama, S. Kato, Evaluation method for predicting dynamic collapse of double layer latticed space truss structures due to earthquake motion. International Journal of Space Structures, Vol.15, 2000, pp.249-257.

[3] S. Okubo, Y, Hiyama, K. Ishikawa, R. Wendel, L. Fischer, Load capacity and plastic deformable ability of aluminum alloy double layer latticed wall subjected to plane load, IASS Symposium 2001, Nagoya, TP101, 2001.

[4] K. Ishikawa, S. Kato, Elastic-plastic buckling analysis of reticular dome subjected to earthquake motion. International Journal of Space Structures, Vol.12, 1997 , pp. 205-215.

[5] Y. Taniguchi, P. L. Gould, M. Kurano, Earthquake input energy at dynamic collapse for double-layer cylindrical Lattice roofs. Journal of the IASS, Vol.49,No. 2, 2008.

[6] F. Fan, Z. Shen, G. Parke Theoretical and experimental study of vibration reduction in braced domes using a viscous damper system. International Journal of Space Structures, Vol.19, No.4, 2004, pp. 195-202.

[7] M. Midorikawa, Performace-based seismic design provisions for buildings in japan. Proceedings of the IASS 2005, Vol.I, 2005, pp.307-316.

[8] G C. Giuliani, Overview on the dynamic control of structures. Proceedings of the IASS 2002, 2002, pp. 561-567.

[9] Z P. Zeng, Structural analysis and design of the latticed shell for Fujian Gymnasium. Journal of Spatial Structures, Vol.13, No.2, 2007, pp. 44-48.

[10] L. Ilzarbe, M.J. E.Álvarez,, M. Viles Tanco, Practical 

Horizontal Earthquake Motions

applications of design of experiments in the field of engineering. Abibliographical review, Qual. Reliab. Engng.Int., Vol.24, 2008, pp.417-428.

[11] European Committee for Standardization (CEN),
Eurocode 8: Design of structures forearthquake resistance Part 1: General rules, seismic actions and rules for buildings (EN 1998-1: 2004). Brussel, 2004. 